DOI: $10.6060 / \mathrm{rcj} .2021653 .11$

УДК: $678.6: 67.02$

\title{
ИССЛЕДОВАНИЯ ТЕРМИЧЕСКИХ ХАРАКТЕРИСТИК ПОЛИАРИЛЕНКЕТОНОВ
}

\author{
А.В. Саморядов ${ }^{1}$, Е.Д. Лукашенко ${ }^{2}$, Е.В. Калугина ${ }^{2}$, В.В. Шапошникова ${ }^{3}$
}

${ }^{1}$ Федеральное государственное бюджетное учреждение науки Межведомственный центр аналитических исследований в области физики, химии и биологии при Президиуме РАН, ул. Профсоюзная, д. 65, стр. 6 , Москва, Российская Федерация, 117342

E-mail: a2612sam@yandex.ru

${ }^{2}$ Общество с ограниченной ответственностью «Группа ПОЛИПЛАСТИК», ул. Генерала Дорохова, д. 14, Москва, Российская Федерация, 119530

E-mail: egor.lukashenko@polyplastic.ru, kalugina@polyplastic.ru

${ }^{3}$ Федеральное государственное бюджетное учреждение науки Институт элементоорганических соединений им. А.Н. Несмеянова РАН, ул. Вавилова, 28, Москва, Российская Федерация, 119991

E-mail:vsh@ineos.ac.ru

Приведены термические характеристики полиариленкетонов различного химического строения.

Ключевые слова: полиариленкетоны, полиэфирэфиркетон, термостойкость

\section{INVESTIGATION OF THE THERMAL CHARACTERISTICS OF POLYARYLENE KETONES}

\author{
A.V. Samoryadov ${ }^{1}$, E.D. Lukashenko ${ }^{2}$, E.V. Kalugina ${ }^{2}$, V.V. Shaposhnikova ${ }^{3}$
}

${ }^{1}$ Interdepartmental Center for Analytical Research in Physics, Chemistry, and Biology, Presidium RAS, Profsoyuznaya str., 65, Moscow, Russian Federation, 117342

E-mail: a2612sam@yandex.ru

${ }^{2}$ Moscow, Russia. Group POLYPLASTIC, LLC, Generala Dorokhova str., 14, Moscow, Russian Federation, 119530

E-mail: egor.lukashenko@polyplastic.ru,kalugina@polyplastic.ru

${ }^{3}$ A.N. Nesmeyanov Institute of Organoelement Compounds of RAS, Vavilova str., 28, Moscow, Russian Federation, 119991

E-mail: vsh@ineos.ac.ru

Thermal properties of polyaryleneketones different chemical structure are investigated.

Key words: polyaryleneketone, polyetheretherketone, thermal resistance

Для цитирования:

Саморядов А.В., Лукашенко Е.Д., Калугина Е.В., Шапошникова В.В. Исследования термических характеристик полиариленкетонов. Рос. хим. ж. (Ж. Рос. хим. об-ва). 2021. T. LXV. № 3. С. 79-84

For citation:

Samoryadov A.V., Lukashenko E.D., Kalugina E.V., Shaposhnikova V.V. Investigation of the thermal characteristics of polyarylene ketones. Ros. Khim. Zh. 2021. V. 65. N 3. P. 79-84

Основной мировой тенденцией последних десятилетий в полимерной отрасли является широкое применение литьевых пластмасс взамен традиционных материалов $[1,2]$. При этом наиболее быстрыми темпами (8-10\% в год) растут объемы производства и применения высокотермостойких термопластов (ВТТ), что обусловлено уникальным сочетанием их технологических и эксплуатационных свойств [1-6]. К настоящему времени промышленное производство и применение нашли композиционные материалы на основе полиариленкетонов (в основном полиэфирэфиркетон), полифениленсульфида и полиэфиримида: основными 
потребителями пластиков на основе ВТТ в мире являются электротехника и электроника, автомобильная и аэрокосмическая отрасли, военная техника и др. динамично развивающиеся сектора экономики [3-6]. Производство указанных материалов осуществляется десятками предприятий, а их марочный ассортимент превышает сотни наименований $[7,8]$.

В последние годы интерес в России к материалам на основе ВТТ значительно возрос и к настоящему времени освоены в опытно-промышленном производстве композиционные материалы на основе полифениленсульфида [5], а в АО «Институт пластмасс имени Г.С. Петрова» освоено опытное производство полиэфирэфиркетона (ПЭЭК) и композиций на его основе $[9,10]$.

Практический интерес к полиэфирэфиркетону (ПЭЭК) марки PEEK Victrex, разработанному в начале 70-х годов прошлого века компанией ICI (Великобритания), подкрепленный применением данного полимера, в первую очередь, предприятиями авиакосмического профиля, постоянно растет и к настоящему времени производство РЕEК ПЭЭК Victrex и композитов на его основе осуществляется более 10 компаниями нескольких стран, а годовой объем производства превысил 6 тыс. т [4, 6-8].

Вместе с тем, несмотря на широкое распространение ПЭЭК Victrex следует отметить, что в настоящему времени синтезировано большое количество полиариленкетонов самого различного химического строения, в т.ч. полимеры, по уровню характеристик превышающее промышленный ПЭЭК Victrex [6].

Исходя из того, что одним из основных преимуществ ПЭЭК, обусловивших его применение, является способность перерабатываться высокопроизводительными методами литья под давлением и экструзии при высоких температурах, составляющих $350-380{ }^{\circ} \mathrm{C}$, данная работа посвящена исследованиям термических характеристик полиариленэфиркетонов (ПАЭК) различного строения.

\section{ОБЪЕКТЫ И МЕТОДЫ ИССЛЕДОВАНИЙ}

Для проведения исследований нами были использованы образцы полиариленкетонов (ПАЭК) в виде пленок, синтезированные в ИНЭОС имени А.Н. Несмеянова РАН, следующего строения:<smiles>CC(C)(C)Oc1ccc(Oc2ccc(OC(C)(C)C)cc2)cc1</smiles>

основные характеристики которых приведены в табл. 1.
Таблица 1

Характеристика модельных образцов полиариленкетонов ПАЭК

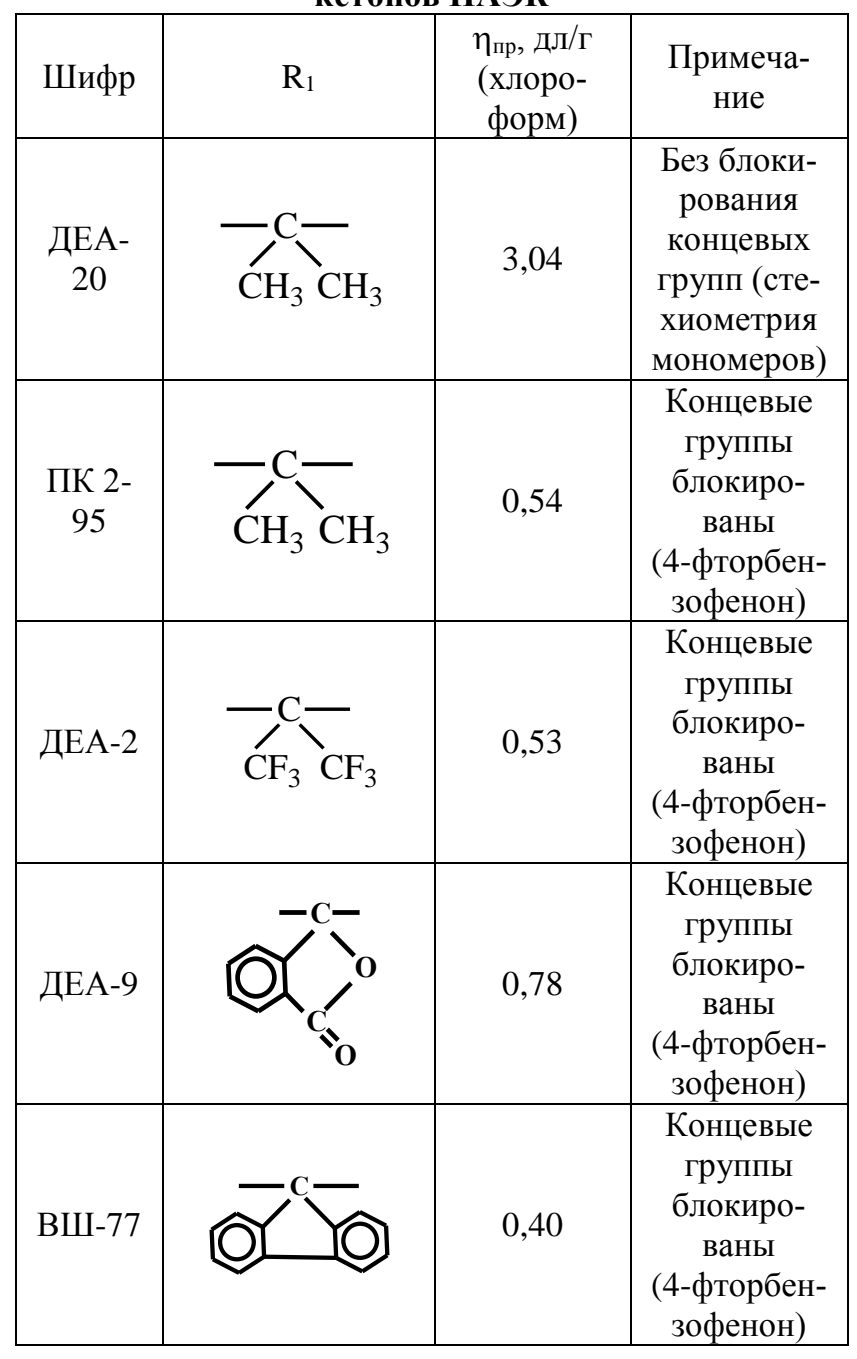

В качестве объектов исследований был также использован сополиариленкетон (шифр ЕТ-5) общей формулы:

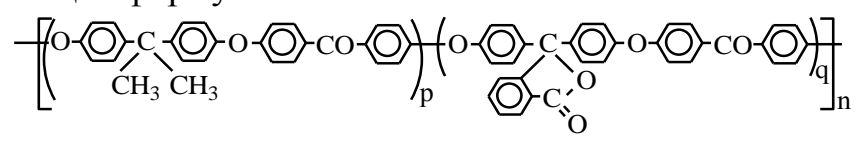

с равным соотношением структурных звеньев $(\mathrm{p} / \mathrm{q}=0,5 / 0,5)$, приведенной вязкостью (хлороформ) 0,75 дл/г, концевые группы которого блокированы 4-фторбензофеноном.

В качестве объектов сравнения были использованы полиэфирэфиркетоны промышленного производства в гранулированной форме:

- марки PEEK Victrex 150G;

- ПЭЭК производства АО «Институт пластмасс имени Г.С. Петрова»;

- алифатический полиэфирэфиркетон POK, HYOSUNG CORP. 


\section{МЕТОДИКИ ИССЛЕДОВАНИЯ}

Термогравиметрический анализ (ТГА) полимеров проводили на установке синхронного термического анализа модели STA 449 F5 Jupiter фирмы NETZESCH в соответствии с ГОСТ 9.715 при скорости подъема температуры $2,5,10$ и $20^{\circ} \mathrm{C} /$ мин., атмосфера - воздух.

Качественный состав выделяющихся при нагревании летучих соединений определяли методом ГХ-МС с помощью хромато-масс-спектрометра ф. Thermo Scientific: газовый хроматограф марки Trace 1310, масс-детектор марки ISQ. Условия хроматографического анализа: капиллярная колонка TG-5MS ф. Thermo Scientific длиной 30 м, с внутренним диаметром 0,25 мм и толщиной фазы 0,5 мкм; газ-носитель - гелий, со скоростью потока 1 мл/мин, инжектор - с делением потока/без деления потока (split/splitless) в режиме деления потока, температура инжектора $-280{ }^{\circ} \mathrm{C}$, температура переходной линии $-280^{\circ} \mathrm{C}$, температура ионного источника $-200{ }^{\circ} \mathrm{C}$. Программируемое изменение температуры термостата газового хроматографа: 5 мин. изотерма при $50{ }^{\circ} \mathrm{C}$, нагрев со скоростью $10^{\circ} \mathrm{C} /$ мин. до $280^{\circ} \mathrm{C}, 10$ минут изотерма при $280{ }^{\circ} \mathrm{C}$.
Навеску образца 50 мг помещали в виалу, герметично закрывали обжимной металлической крышкой и нагревали при температуре $200{ }^{\circ} \mathrm{C}$ в течение 30 минут с периодическим встряхиванием, пробу отбирали парофазным методом с помощью автоматической приставки для парофазного анализа TriPlusRSH Autosampler $ф$. Thermo Scientific.

\section{РЕЗУЛЬТАТЫ ИССЛЕДОВАНИЙ}

\section{Термогравиметрический анализ}

Термические характеристики ПАЭК исследовались методом термогравиметрического анализа в широком диапазоне температур и скоростей подъема температуры, при этом особое внимание уделялось исследованию термического поведения ПАЭК в области температур, близких к температуре переработки $\left(350-380^{\circ} \mathrm{C}\right)$ из расплава. Как видно из ТГА-данных, приведенных в табл. 2 и на рис. 1 все исследованные полиариленэфиркетоны имеют очень высокую термостойкость: температура начала разложения при оценке по пересечению касательных к термогравиметрической кривой в соответствии с ГОСТ 29127 превышает $380{ }^{\circ} \mathrm{C}$. С увеличением скорости нагрева кривые ТГА смещаются в более высокотемпературную область.

Таблица 2

Показатели термостойкости ПАЭК при разных скоростях подъема температуры

\begin{tabular}{|c|c|c|c|c|c|c|c|c|c|}
\hline \multirow{2}{*}{$\begin{array}{c}\text { Скорость } \\
\text { нагрева, } \\
{ }^{\circ} \mathrm{C} / \text { мин }\end{array}$} & \multicolumn{9}{|c|}{ Температура начала разложения, ${ }^{\circ} \mathrm{C}$} \\
\hline & ДЕА-20 & $\begin{array}{c}\text { ПК } \\
2-95\end{array}$ & ДЕА-2 & ДЕА-9 & $\begin{array}{c}\text { ВШ- } \\
77\end{array}$ & ET-5 & $\begin{array}{c}\text { Victrex } \\
150 \mathrm{G}\end{array}$ & POK & ПЭЭК \\
\hline 2 & 388,7 & 480,1 & 506,3 & 448,3 & 504,5 & 431,1 & 531,1 & 319,2 & 518,6 \\
\hline 5 & 404,0 & 495,9 & 509,9 & 464,5 & 525,9 & 454,7 & 550,7 & 349,2 & 537,5 \\
\hline 10 & 415,8 & 507,9 & 512,4 & 472,2 & 537,1 & 468,3 & 564,8 & 367,1 & 549,4 \\
\hline 20 & 427,8 & 514,4 & 513,3 & 476,8 & 541,0 & 477,2 & 572,8 & 384,4 & 557,8 \\
\hline
\end{tabular}

Процесс термоокислительной деструкции ПАЭК протекает в две стадии, не зависимо от химического строения полимеров. На первой стадии массовые потери составляют 20-35 масс.\%, после чего на дифференциальной кривой ТГА наблюдается перегиб, который обычно связывают с образованием в ходе окисления более стабильной, по сравнению с исходной, структуры, либо с исчерпанием фрагментов наиболее подверженных окислению. Затем на второй стадии происходит деструкция практически без образования коксового остатка. Характер разложения исследованных образцов ПАЭК сохраняется в исследованном диапазоне скоростей: имеет место двухстадийное разложение с более выраженной ступенью при повышении скорости разложения на второй стадии.

Из анализа приведенных данных ТГА следует, что самая низкая термостойкость отмечена у ДЕА$20\left(388,7{ }^{\circ} \mathrm{C}\right)$ - образца с высокой молекулярной массой и незаблокированными концевыми группами, блокирование которых 4-фторбензофеноном приводит к значительному повышению показателя термостойкости ПАЭК (табл. 2) - на 50$120{ }^{\circ} \mathrm{C}$ в зависимости от строения ПАЭК. Замена 
метиленовых групп (ПК 2-95) на фторзамещенные (ДЕА-2) обеспечивает ПАЭК самую высокую термостойкость среди исследованных полимеров. Введение в структуру ПАЭК кардовых фрагментов (ДЕА-9) существенно повышает растворимость получаемых продуктов, что упрощает технологию получения пленок и покрытий из доступных растворителей (хлороформ), но снижает показатели термостойкости: термостойкость ПАЭК, содержащих кардовые фрагменты, снижается в ряду ВШ-77 > ДЕА-9 > сополимер ЕТ-5.

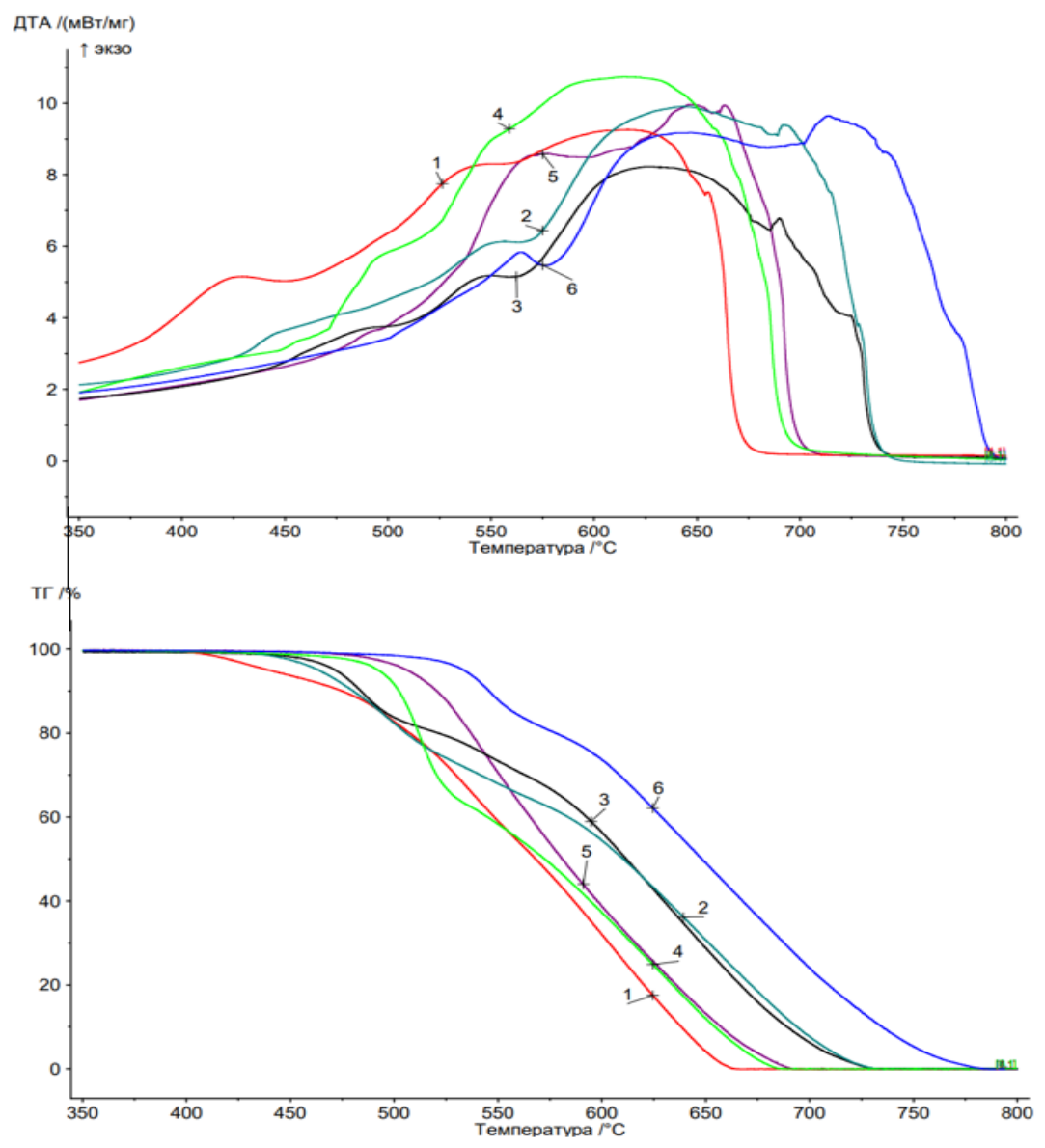

импортному образцу (табл. 2, рис. 2). Сравнение характеристик ароматических ПАЭК с «модным» алифатическим продуктом РОК [11] показывает их значительное преимущество по термостойкости, что вполне ожидаемо: температура начала деструкции РОК незначительно превышает $300{ }^{\circ} \mathrm{C}$, а полного разложения - вблизи $600{ }^{\circ} \mathrm{C}$ (рисунок 2).

Вязкость расплава полимеров оценивали по показателю текучести расплава (ПТР) при $380{ }^{\circ} \mathrm{C}$, нагрузке 5 кг, диаметр капилляра 2,09 мм: ПТР PЕEК Victrex $=80$ г/10 мин, ПТР ПЭЭК $=60$ г/10 мин. Отечественный ПЭЭК характеризуется более низким ПТР, т.е. более высокой вязкостью и, следовательно, большей молекулярной массой.

Данные ИК-спектроскопии (рис. 3) свидетельствуют о полном сходстве химических структур отечественного и импортного ПЭЭК: поглощение в области 1600-1400 $\mathrm{cm}^{-1}$ (полосы при 1593, 1488 и $1411 \mathrm{~cm}^{-1}$ ), относится к скелетным колебаниям ароматических С-С- связей, деформационные колебания С-Н проявляются при 1125-1080 $\mathrm{cm}^{-1}$, интенсивная полоса при $1648 \mathrm{~cm}^{-1}$ относится к колебаниям $\mathrm{C}=\mathrm{O}$, ассиметричные валентные колебания Ar-O-Ar проявляются при 1011 и $1010 \mathrm{~cm}^{-1}$, слабые полосы в диапазоне 3099-3044 $\mathrm{cm}^{-1}$ соответствуют колебаниям С-Н. Полосы 1448, 623, 602 и $563 \mathrm{~cm}^{-1}$, вероятно, относятся к остаткам растворителя - дифенилсульфона.

Несмотря на практически полную идентичность ИК-спектров PEEK Victrex и ПЭЭК (рис. 3) не исключено, что разница в термостойкости импортного и отечественного

Рис. 1. Динамический ДТА/ТГА на воздухе при скорости нагрева $5{ }^{\circ} \mathrm{C}$ /мин образцов ПАЭК:

1 - ДЕА-20, 2 - ЕТ-5, 3 - ДЕА-9, 4 - ПК 2-95, 5 - ДЕА-2, $6-$ ВШ-77

Кроме повышения показателей термостойкости, блокирование концевых групп существенно повышает термостабильность и улучшает перерабатываемость расплава [4], что очень важно для получения перерабатываемых литьем под давлением и экструзией композитов на основе ПАЭК.

Сравнение промышленных полимеров марки PEEK Victrex и отечественного ПЭЭК показало, что отечественный продукт немного (примерно на $10-13{ }^{\circ} \mathrm{C}$ ) уступает по показателям термостойкости полимеров связана с тем, что в импортном образце концевые группы блокированы.

\section{ГХ-МС исследования}

Идентификация летучих продуктов и примесей, содержащихся в ПАЭК (остатки растворителей от синтеза и промывки полимеров, влага, сорбируемая при хранении и т.д.) очень важна для материалов, перерабатываемых из расплава, поскольку состав примесей влияет прежде всего на их термостабильность в расплаве. Причем, примеси различного состава могут по-разному влиять на свойства, например, если в процессе синтеза в качестве побочных продуктов образуются пероксиды или гидроксиламины, то при экструзии и компаундировании могут протекать реакции сшивания, а 
остатки плавких растворителей, таких как, дифенилсульфон, могут пластифицировать полимер, облегчая перерабатываемость, но снижая его термостабильность.

Хромато-масс-спектрометрические исследования выделяющихся при нагревании (температура $200{ }^{\circ} \mathrm{C}, 30$ мин) летучих соединений из образцов ПАЭК показали, что, несмотря на высокую термостойкость из всех полимеров до температуры их переработки выделяется 0,2-0,3 масс.\% летучих соединений, основными продуктами среди которых являются 4,4'-дифторбензофенон - фторсодержащий мономер, использующийся при проведении поликонденсации, хлорбензол, использованный как азеотропообразователь и хлороформ, который применяли для выделения полимеров в виде пленки и незначительные органические примеси в следовых количествах.
В составе летучих, идентифицированных из промышленного отечественного образца ПЭЭК обнаружено только заметное количество остаточного растворителя дифенилсульфона - интенсивный пик при времени выхода 24,7 мин, что согласуется с данным ИК-спектроскопии, и тетрахлорэтилен, вероятно, использованный для отмывки. В импортном образце РЕEК Victrex также в заметных количествах обнаружена примесь тетрахлорэтилена (время удерживания на хроматограмме 7,43 мин) и 4,4'-дифторбензофенона.

Важно отметить, что отечественный полимер более чистый по сравнению с импортным аналогом, но содержание дифенилсульфона в отечественном образце выше, чем в импортном: содержание летучих продуктов в РЕЕК Victrex составляет 0,218 масс.\%, а в ПЭЭК - 0,283 масс.\%.

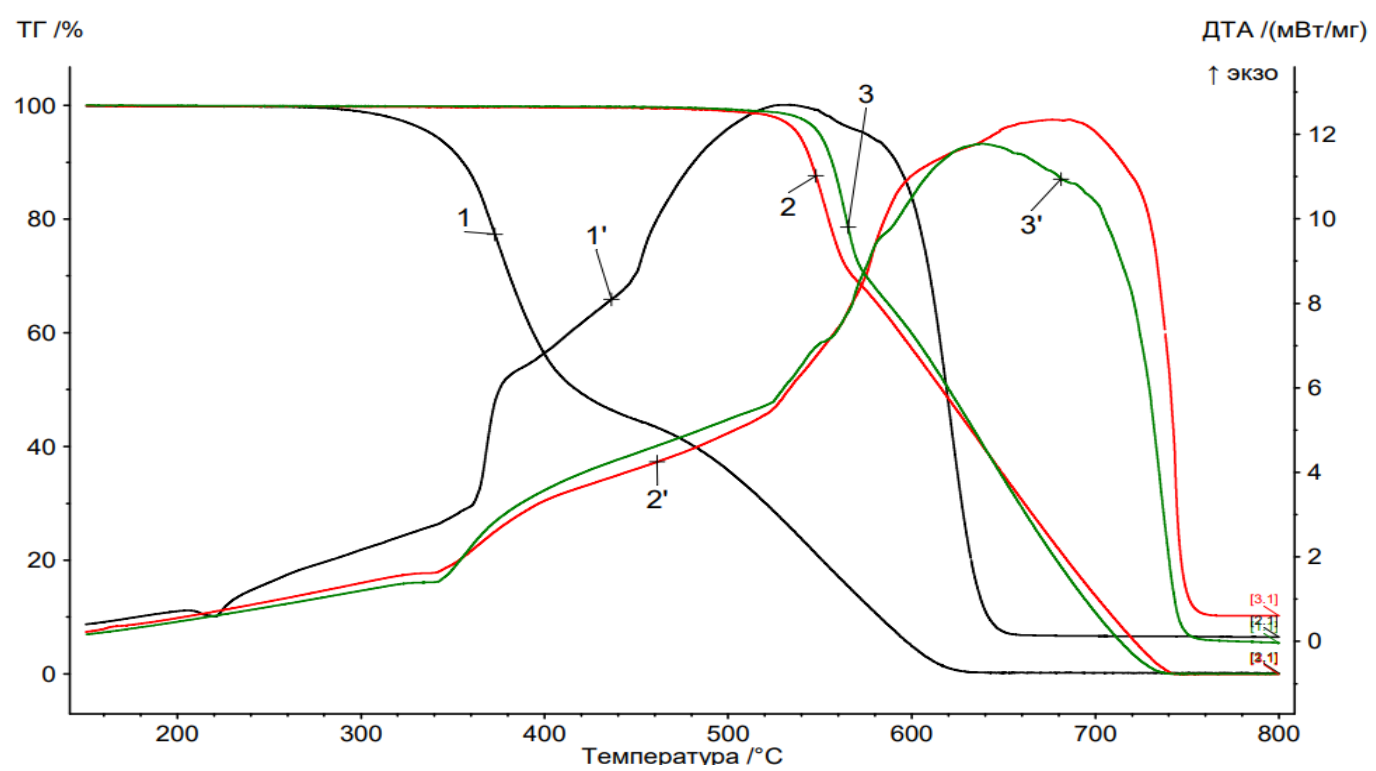

Рис. 2. Динамический ТГА на воздухе при скоростях нагрева $20^{\circ} \mathrm{C} /$ мин в диапазоне температур $200-650{ }^{\circ} \mathrm{C}$ : 1, $1^{\prime}$ - РОК, 2, 2' - ПЭЭК, 3, 3' - РЕЕК Victrex

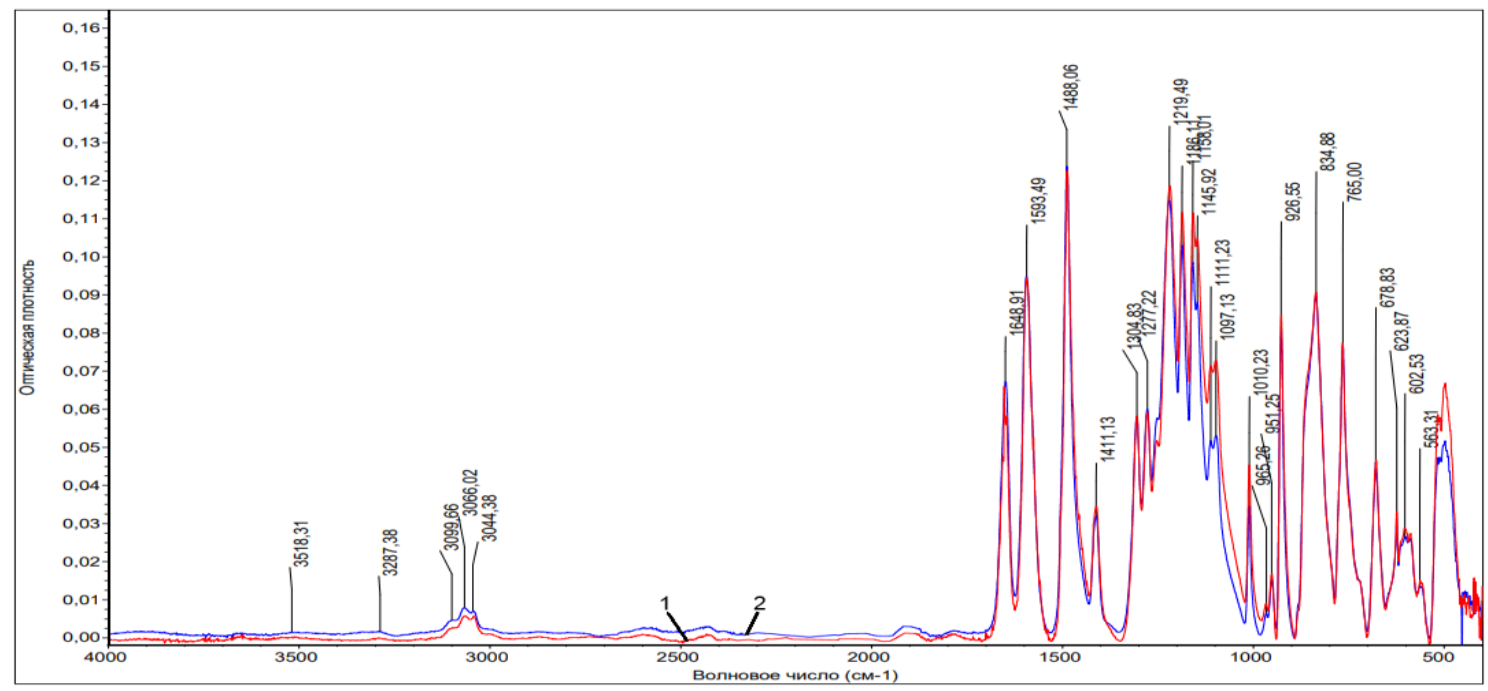

Рис. 3. Оригинальные ИК спектры отечественного ПЭЭК (1) и РЕЕК Victrex (2) 


\section{ЗАКЛЮЧЕНИЕ}

Методом ТГА исследованы термические характеристики ПАЭК различного химического строения в широком диапазоне температур и скоростей подъема температуры. Показано, что все исследованные ПАЭК характеризуются высокой термостойкостью.

Установлено, что блокирование концевых групп ПАЭК позволяет существенно повысить показатели термостойкости ПАЭК, что способствует улучшению их перерабатываемости из расплава.

Хромато-масс-спектрометрическим анализом установлено, что, несмотря на высокую термостойкость, из всех полимеров до температуры их

\section{ЛИТЕРА Т УРА}

1. Михайлин Ю.А. Термоустойчивые полимеры и полимерные материалы. СПб.: Профессия, 2006. 624 с.

2. Михайлин Ю.А. Специальные полимерные композиционные материалы. СПб.: Научные основы и технологии, 2009. $660 \mathrm{c}$.

3. Тенденции рынка полифениленсульфида в мире и России. Евразийский химический рынок. 2013. № 10(109). C. 24-30.

4. Мировое производство и рынок полиэфирэфиркетонов. Евразийский химический рынок. 2016. № 5 (140). С. 3-27.

5. Саморядов А.В., Иванов В.Б., Калугина Е.В. Свойства и применение стеклонаполненных полифениленсульфидов. Российский химический журнал. 2020. Т. 64. № 4. С. 3-19. DOI: 10.6060/rcj.2020644.1.

6. Салазкин С.Н., Шапошникова В.В. Полиариленэфиркетоны - термо-, тепло- и хемостойкие термопласты и перспективы создания различных материалов на их основе Высокомолекулярные соединения (Серия С). 2020. Т. 62. № 2. C. 108-121. DOI: 10.31857/S2308114720020120.

7. Барвинский И.А., Барвинская И.Е. Справочник по литьевым термопластичным материалам / Сайт: www.barvinsky.ru.

8. База полимеров / Сайт: www.plasinfo.ru.

9. Полиэфирэфиркетон. Технические характеристики / сайт: www.instplast.ru>poliefirefirketon.

10. Гуреньков В.М., Горшков В.О., Чеботарев В.П., Прудскова Т.Н., Андреева Т.И. Сравнительный анализ свойств полиэфирэфиркетона отечественного и зарубежного производства. Авиационные материалы и технологии. 2019. № 3 (56). С. 41-44.

11. Зайферт Х., Верле М. Алифатические поликетоны - новое семейство полимеров для технических областей применения. Полимерные материалы. 2014. № 10. С. 40-47. переработки выделяется 0,2-0,3 масс.\% летучих соединений, основными продуктами среди которых являются остатки растворителей, используемых при их синтезе, отмывке и др. технологических операций.

Для применения ПАЭК в качестве основы композиционных материалов, перерабатываемых методами литья под давлением и экструзии следует совершенствоать технологию их подготовки, исключающую выделение летучих продуктов.

Работа по синтезу полимеров выполнена при поддержке Министерства науки и высшего образования Российской Федераџии.

\section{REFERENCES}

1. Mikhailin, Yu.A. Termoustoichivye polymery $i$ polymernye materialy. Sankt-Peterburg: Professiya, 2006. 624 p.

2. Mikhailin, Yu.A. Specialnye polymernye kompozicionnye materialy. Sankt-Peterburg: Nauchnye osnovy i tehnologii. 2009. 660 p.

3. Tendencii rynka polyphenylensulfida v mire i Rossii. Evraziiskii himicheskii rynok. 2013. N 10(109). P. 24-30.

4. World production and market of polyethereterketons. Evraziiskii khimicheskii rynok. 2016. N 5 (140). P. 3-27.

5. Samoryadov A.V., Ivanov V.B., Kalugina E.V. Bulk properties and application of glass fiber filled polyphenylenesulfide. Rossiiskii khimicheskii journal. 2020. V. 64. N 4. P. 3-19. DOI: 10.6060/rcj.2020644.1.

6. Salazkin S.N., Shaposhnikova V.V. Poly(arylene ether ketones): Thermostable, Heat Resistant, and Chemostable Thermoplastics and Prospects for Designing Various Materials on Their Basis, Visokomolekulyarnye soedineniya (Seriya C). 2020. V. 62. N 2. P. 108-121. DOI: $10.31857 /$ S2308114720020120.

7. Barvinskii I.A., Barvinskaya I.E. Spravochnik po lityevim termoplastichnim materialam / www.barvinsky.ru.

8. Baza polymerov / www.plasinfo.ru.

9. Polyetheretherketone. Technical properties / www.instplast.ru>poliefirefirketon.

10. Gurenkov V.M., Gorshkov V.O., Chebotaryev V.P., Prudskova T,N., Andreeva T.I. Comparative analysis of properties polyetheretherketone Russian and foreign manufacture. Aviacionnye materialy i tehnologii. 2019. N 3 (56). P. 41-44.

11. Zeifert H., Verle M. Alyphatic polyketons - new family for technical applications. Polymerniye materialy. 2014. N 10. P. 40-47.

Поступила в редакиию (Received) 01.08.2021

Принята к опубликованию (Accepted) 03.09.2021 